\title{
Trabalho e precarização nos museus brasileiros: uma análise introdutória ${ }^{1}$ \\ Wagner Miquéias ${ }^{2}$
}

\section{Resumo:}

Este estudo é uma reflexão inicial sobre a situação do trabalhador museólogo no Brasil e está nos marcos da Sociologia do Trabalho. Utilizo dados da pesquisa realizada pelo Instituto Brasileiro de Museus (IBRAM), Museus em Números, para visualizar a situação dos museólogos nas instituições museológicas brasileiras, localizando tal situação num cenário econômico nacional e internacional. Desenvolvo uma breve incursão nas reflexões contemporâneas sobre o mundo do trabalho e suas transformações, pretendendo, com isso, escolher certas categorias para caracterizar os museólogos e compreendê-los

${ }^{1}$ Este texto foi apresentado, originalmente sob o nome $A$ situação dos trabalhadores museólogos brasileiros, no GT Trabalho e Sindicalismo, do VI Seminário Nacional de Sociologia e Política, realizado pela Universidade Federal do Paraná, em Curitiba, no ano de 2015.

2 Bacharel em Museologia pela Universidade Federal do Estado do Rio de Janeiro (UNIRIO). Graduado em Ciências Sociais pela Universidade Federal do Rio de Janeiro (UFRJ), Mestre em Ciências Sociais, Desenvolvimento, Agricultura e Sociedade pelo CPDA/UFRRJ. Fui bolsista de Iniciação Científica pela UNIRIO (2005-2006), bolsista PIBIC-CNPq (2006-2007), bolsista AT-CNPq (2008-2009) e bolsista de Mestrado do CNPq (2009-2011). Sou professor efetivo da Coordenadoria Especial de Museologia da Universidade Federal de Santa Catarina (UFSC). Ministro aulas nas cadeiras de Teoria e Comunicação Museológica e desenvolvo pesquisas sobre a História dos Museus e sobre o mundo do trabalho na Museologia. Desenvolvo pesquisas acerca da Formação dos Museus e sobre o mundo do trabalho na Museologia wagnermiqueias@yahoo.com.br 
no mundo de trabalho. Privilegiarei, aqui, os estudos dos sociólogos brasileiros Ricardo Antunes e Ruy Braga e do economista inglês Guy Standing, pois tratam do tema da precarização do trabalho combinando os referenciais da Economia Política e da Sociologia do Trabalho.

Palavras-chave: museólogos, museus, precarização, precariado, trabalho.

\begin{abstract}
:
This study is an initial reflection on the situation of museologists workers in Brazil and is within the framework of the Labour Sociology. Use data from the survey conducted by the Brazilian Institute of Museums (IBRAM), Museums in Numbers, to view the status of museologists in museums institutions, locating such a situation a national and international economic scenario. Develop a brief foray into contemporary reflections on the world of work and its transformations, intending choose certain categories to characterize the museologists and understand them in the world of work. Will privilege studies of Brazilian sociologists Ricardo Antunes and Ruy Braga and English economist Guy Standing, because dealing with the issue of precarious work combining the references of Political Economy and Labour Sociology.
\end{abstract}

Keywords: museologists, museums, precarization, precariat, work.

Este estudo é uma reflexão inicial sobre a situação do trabalhador museólogo no Brasil e está nos marcos da Sociologia do Trabalho. Utilizo dados das pesquisas realizadas pelo Instituto Brasileiro de Museus (IBRAM), Museus em Números, e Museus e a dimensão econômica, para visualizar a situação dos museólogos nas instituições museológicas brasileiras, localizando tal situação num cenário econômico nacional e internacional.

Desenvolvo uma breve incursão nas reflexões contemporâneas sobre o mundo do trabalho e suas transformações, pretendendo, com isso, escolher certas categorias para caracterizar os museólogos e compreendê-los no mundo do trabalho. É importante destacar que esse é um esforço inicial e, por isso, a adequação das categorias e da proposta metodológica será testada em estudos posteriores mais focalizados. Privilegiarei, aqui, os estudos dos sociólogos 
brasileiros Ricardo Antunes e Ruy Braga e do economista inglês Guy Standing, pois entendo que tratam do tema da precarização do trabalho a partir de uma perspectiva que combina os referenciais da Economia Política e da Sociologia do Trabalho.

\section{O precariado e a precarização na Sociologia do Trabalho contemporânea}

A tese do sociólogo Ricardo Antunes é que emerge a partir da segunda metade do séc. XX novas práticas de exploração dos trabalhadores, novos arranjos produtivos, que configuram uma nova morfologia do trabalho. Para tanto, formula o conceito classe-que-vive-do-trabalho, que abarca a totalidade daqueles que vendem a sua força de trabalho, ou seja, engloba os trabalhadores produtivos e improdutivos, mas tem como núcleo central os trabalhadores produtivos (no sentido marxiano de produzir mais-valia).

Considerando, portanto, que todo trabalhador produtivo é assalariado e nem todo trabalhador assalariado é produtivo, uma noção contemporânea de classe trabalhadora, vista de modo ampliado, deve, em nosso entendimento, incorporar a totalidade dos trabalhadores assalariados. Isso não elide, repetimos, o papel de centralidade do trabalhador produtivo, do trabalho social coletivo, criador de valores de troca, do proletariado industrial moderno no conjunto da classe-que-vive-do-trabalho, o que nos parece por demais evidente quando a referência é dada pela formulação de Marx (2009, p. 103).

Uma noção ampliada de classe trabalhadora, para Antunes (2009), deve incluir todos aqueles que vendem a sua força de trabalho em troca de um salário, além dos proletários industriais, dos assalariados do setor de serviços, o proletariado rural, o proletariado precarizado, o subproletariado moderno, 
part time, o novo proletariado dos McDonald's, os trabalhadores da economia informal e os infoproletários.

Os contornos mais gerais, analíticos e empíricos da nova morfologia do trabalho, definidos por Antunes, são os seguintes: a retração do binômio taylorismo/fordismo e o aumento do trabalho precarizado, assim definido por Antunes: "são os terceirizados, subcontratados, part-time, entre tantas outras formas assemelhadas, que se expandem em escala global". Sinteticamente, o desenho dessa nova morfologia do trabalho, para o autor, possui os seguintes traços: 1 ) retração do modelo de trabalhador taylorista/fordista e ampliação de formas desregulamentadas de trabalho, mais instáveis e informais; 2) crescimento do trabalho precarizado nas fábricas e no setor de serviços; 3) aumento do trabalho feminino, com remuneração inferior e com forte traço precário; 4) expansão dos assalariados médios no "setor de serviços", repelidos do mundo produtivo industrial; 5) interrelação crescente entre o mundo produtivo e setor de serviços; 6) exclusão dos jovens em condições de trabalhar, que engrossam as fileiras do trabalho precarizado e do desemprego; 7) exclusão dos considerados "idosos", com idade próxima de quarenta anos, que experimentam dificuldades crescentes de reingresso no mercado de trabalho, quando desempregados; 8) incremento do trabalho infantil; 9) crescente expansão do trabalho no "terceiro setor", com empresas de perfil mais comunitário, que lançam mão de trabalho voluntário, sem fins lucrativos e à margem do mercado formal; 10) expansão do trabalho em domicílio.

Sobre os trabalhadores improdutivos (que não criam diretamente mais-valia, por servirem, seja na esfera pública, seja na esfera propriamente capitalista) assim nos fala Antunes:

Podemos também acrescentar que os trabalhadores improdutivos, criadores de antivalor no processo de trabalho, vivenciam situações muito aproximadas com aquelas experimentadas pelo conjunto dos 
trabalhadores produtivos. A classe trabalhadora hoje incorpora tanto os trabalhadores materiais como aqueles e aquelas que exercem trabalho imaterial, predominantemente intelectual (2007, p. 21).

Os trabalhadores museólogos, de conjunto, são trabalhadores improdutivos ${ }^{3}$, isto é, não produzem mercadorias e não produzem mais-valia. Porém, realizam serviços que, de uma maneira global, colaboram para o funcionamento da sociedade. Portanto, seguindo as elaborações de Antunes, comporiam a classe-que-vive-do-trabalho e, consequentemente, inserida - e esta pesquisa tentará apontar isso - nas transformações do mundo do trabalho contemporâneo.

Ricardo Antunes se concentra no processo de precarização, ao qual, a classe-que-vive-do-trabalho está cada vez mais sujeita. Diferentemente, o economista Guy Standing compreende o precariado como uma condição (seja como classe ou pelo status) e como um processo, embora privilegie, em sua análise de conjunto, o precariado como uma condição.

Para Guy Standing o precariado é a nova classe perigosa. Uma nova classe que possui relações mínimas de confiança no Estado e no capital, constituindo um status truncado. De acordo com o economista britânico, o precariado consiste em pessoas que são desprovidas de sete formas de garantias relacionadas ao trabalho, apresentadas no quadro abaixo. Em suas palavras, "nem todos aqueles que fazem parte do precariado valorizariam todas as sete formas de segurança, mas se saem mal em todos os aspectos" (2014, p. 28).

\footnotetext{
${ }^{3}$ Nunca é demais explicar que os termos produtivos e improdutivos se referem, na perspectiva marxista, à mais-valia, um valor a mais que é criado pelo trabalho não pago o que caracteriza a forma de produção capitalista de mercadorias: "A mais-valia se origina de um excedente quantitativo de trabalho, da duração prolongada do mesmo processo de trabalho, tanto no processo de produção de fios quanto no processo de produção de artigos de ourivesaria (MARX, 2008, p. 231).
} 


\begin{tabular}{|c|l|}
\hline $\begin{array}{c}\text { Tabela } 1 \text { - Formas de garantia e segurança de trabalho nos } \\
\text { termos da cidadania industrial }\end{array}$ \\
\hline $\begin{array}{c}\text { Garantia de } \\
\text { mercado de } \\
\text { trabalho }\end{array}$ & $\begin{array}{l}\text { Oportunidades adequadas de renda-salário; no nível macro, } \\
\text { isto é realçado por um compromisso governamental de } \\
\text { "pleno emprego". }\end{array}$ \\
\hline $\begin{array}{c}\text { Garantia de } \\
\text { vínculo } \\
\text { empregatício }\end{array}$ & $\begin{array}{l}\text { Proteção contra a dispensa arbitrária, regulamentação } \\
\text { sobre contratação e demissão, imposição de custos aos } \\
\text { empregadores por não aderirem às regras e assim por } \\
\text { diante. }\end{array}$ \\
\hline $\begin{array}{c}\text { Segurança no } \\
\text { emprego }\end{array}$ & $\begin{array}{l}\text { Capacidade e oportunidade para manter um nicho no } \\
\text { emprego, além de normas de segurança e saúde, limites de } \\
\text { tempo de trabalho, horas insociáveis, trabalho noturno para } \\
\text { as mulheres, bem como compensação de contratempos. }\end{array}$ \\
\hline $\begin{array}{c}\text { Segurança do } \\
\text { trabalho }\end{array}$ & $\begin{array}{l}\text { Proteção contra acidentes e doenças no trabalho através, } \\
\text { por exemplo, de normas de segurança e saúde, limites de } \\
\text { tempo de trabalho, horas insociáveis, trabalho noturno para } \\
\text { as mulheres, bem como compensação de contratempos." }\end{array}$ \\
\hline $\begin{array}{c}\text { Garantia de } \\
\text { reprodução de } \\
\text { habilidade }\end{array}$ & $\begin{array}{l}\text { Oportunidade de adquirir habilidades, através de estágios, } \\
\text { treinamento de trabalho, e assim por diante, bem como } \\
\text { oportunidade de fazer uso dos conhecimentos. }\end{array}$ \\
\hline $\begin{array}{c}\text { Segurança de } \\
\text { renda }\end{array}$ & $\begin{array}{l}\text { Garantia de renda adequada e estável, protegida, por } \\
\text { exemplo, por meio de mecanismos de salário mínimo, } \\
\text { indexação dos salários, previdência social abrangente, } \\
\text { tributação progressiva para reduzir a desigualdade e para } \\
\text { complementar as baixas rendas. }\end{array}$ \\
\hline representação & $\begin{array}{l}\text { Possuir uma voz coletiva no mercado de trabalho por meio, } \\
\text { por exemplo, de sindicatos independentes, com o direito de } \\
\text { greve. }\end{array}$ \\
\hline
\end{tabular}

Para Standing, o neoliberalismo e a globalização financeira condicionaram o crescimento e o desenvolvimento à competitividade do mercado inscrevendo suas diretrizes econômicas na agenda política internacional. Mas a principal

${ }^{4}$ Adaptada do quadro elaborado por Standing (2014, p. 28) 
causa direta do crescimento do precariado global, para o economista britânico, é a flexibilidade. Uma das principais características da flexibilidade é o uso crescente do emprego temporário:

O emprego temporário tem vantagens de custo: os salários são mais baixos, evita-se o pagamento com base na experiência, o direito aos benefícios da empresa é menor e assim por diante. E há menos risco; contratar alguém temporariamente não significa assumir um compromisso que possa ser lamentado, por qualquer razão (2014, p. 58).

O crescimento do emprego temporário imprime mudanças nas relações de solidariedade entre os trabalhadores e imprime ritmos de exploração desiguais entre trabalhadores regulares e temporários: "as pessoas contratadas temporariamente podem ser induzidas a trabalhar de forma mais dura, especialmente se os trabalhos são mais intensos do que aquele feito pelos trabalhadores regulares" (2014, p. 58).

Uma outra abordagem do tema é feita pelo sociólogo Ruy Braga que ressignifica o conceito de precariado ao defini-lo como um trabalhador que compõe a superpopulação relativa (excluído o lumpemproletariado e o pauperismo) definida por Karl Marx.

entendemos que em decorrência da mercantilização do trabalho, do caráter capitalista da divisão do trabalho e da anarquia da reprodução do capital, a precariedade é constitutiva da relação salarial. Consequentemente, o precariado não deve ser interpretado como o antípoda do salariado, seu "outro" bastardo recalcado. Na realidade, ele é a própria condição de existência do salariado: tanto na Europa ocidental quanto nos Estados Unidos, o compromisso fordista mostrou-se bastante eficiente em proteger a fração profissional, branca, masculina, adulta, nacional e sindicalizada da classe 
trabalhadora, à custa da reprodução da fração proletária não qualificada ou semiqualificada, feminina, negra, jovem e migrante (2012, p. 17).

Assim, Ruy Braga retoma as análises de Marx feitas no livro 1 d'O Capital sobre a acumulação capitalista e seus aspectos demográficos inerentes 5 .

Braga distingue o precariado dos setores profissionais, isto é, grupos mais qualificados, com melhores remunerações e, por isso, um setor tendencialmente mais estável da classe trabalhadora.

Em suma, identificamos o precariado com a fração mais mal paga e explorada do proletariado urbano e dos trabalhadores agrícolas, excluídos a população pauperizada e o lumpemproletariado, por considerála própria à reprodução do capitalismo periférico (2012, p. 19).

O precariado, para Ruy Braga (2012), seria composto pelos seguintes grupos/características: 1 ) população flutuante; 2 ) população latente; 3) população estagnada; 4) capacidade de mobilização; 5) renda entre 1 a 2 salários mínimos.

Para ele, a precarização não é um processo eminentemente novo. E em termos de condição não se trata de uma nova classe em formação, como anuncia Standing. No que se refere ao engajamento político do precariado, Braga e Standing, embora concordem sobre seu peso social, divergem no que se referem à sua inclinação na luta política.

\footnotetext{
${ }^{5}$ Sobre as leis de população no modo de produção capitalista: "Por isso, a população trabalhadora, ao produzir a acumulação do capital, produz, em proporções crescentes, os meios que fazem dela, relativamente, uma população supérflua. Esta é uma lei da população peculiar ao modo capitalista de produção. Na realidade, todo modo histórico de produção tem suas leis próprias de população, válidas dentro de limites históricos. Uma lei abstrata da população só existe para plantas e animais, e apenas na medida em que esteja excluída a ação humana" (MARX, 2009, p. 735).
} 
Na definição de precariado feita por Braga não são incluídas as categorias profissionais qualificadas. Entretanto, é sabido que certas categorias profissionais encontram-se mais suscetíveis à precarização do que outras, especialmente aquelas que não se substanciam em trabalhadores produtivos, como os museólogos.

Embora possam exercer diferentes atividades, o museu é a principal instituição para o emprego da força de trabalho dos museólogos. Por isso, tratarei da atual situação dos museus brasileiros e, em paralelo, tentarei esboçar o perfil do trabalhador museólogo em consonância com o que já foi exposto até aqui. Assim, tentarei reintroduzir o museu e o museólogo na totalidade do modo de produção capitalista, donde só teoricamente ele fora extraído.

\section{Museus e Estado brasileiro}

A Museologia ${ }^{6}$ apresenta uma forte dependência dos governos e do Estado. Historicamente, os museus brasileiros estão ligados ao Estado, ao passo em que, as políticas de governo incidem diretamente sobre a categoria profissional. Seu ofício está vinculado, também, a ministérios que possuem menos "peso" na estrutura político-econômica do país e que, ao menor sinal de crise, tornam-se prioridade nos cortes orçamentários.

Por isso, não é exagero dizer que a Museologia brasileira, enquanto campo, está historicamente entrelaçada com o Estado, em face dos governos federais, estaduais e municipais deste país ${ }^{7}$.

As políticas públicas de Estado se revestem de particular

\footnotetext{
${ }^{6}$ Designo, aqui, a área de formação dos museólogos. Cumpre dizer que a expressiva expansão do número de cursos universitários de Museologia no Brasil deu-se, em sua quase totalidade, em instituições federais. Em 2005 haviam 03 cursos de graduação em IES no país, e em 2011 já havia o registro de 15 cursos em IES, sendo que 14 eram em instituições de ensino superior federais.

${ }^{7}$ Ver Santos (2004).
} 
interesse para a área. E por ter isso em consideração, a divisão do Orçamento Público Federal torna-se uma questão de fundo.

Os projetos de lei orçamentária elaborados pela União representam o conjunto de compromissos anuais do Estado brasileiro. No ano de 2014, o Projeto de Lei Orçamentária previu um total de despesas em torno de $\mathrm{R} \$ 2,4$ trilhões do Produto Interno Bruto (PIB). Deste valor, $\mathrm{R} \$ 1,356$ trilhão $(45,1 \%)$ foram destinados ao pagamento de juros e amortizações da dívida pública. De acordo com a Auditoria Cidadã da Dívida": "Esse privilégio mostra que o endividamento é o maior problema do gasto público brasileiro, e afeta todas as áreas sociais". Para a Cultura foram executados $0,04 \%$ do orçamento.

A dívida pública ${ }^{9}$ é um mecanismo de dominação perverso. A dívida externa, mais complexa, impõe o pagamento em uma moeda que o país devedor não emite e o submete às oscilações das taxas de juros do país emissor dessa moeda. A dívida impõe uma política social que delega, sempre, menos do que o necessário aos serviços públicos essenciais. Por isso, talvez seja esse o vetor mais determinante para os museus públicos brasileiros e, consequentemente, para os trabalhadores dessas instituições, por dar os contornos econômicos das políticas públicas para a Cultura.

${ }^{8}$ Fonte: Auditoria Cidadã da Dívida. Disponível em: http://goo.gl/KeTLAa. Acesso em: 13 mai 2014. Ver, também: http://www.auditoriacidada.org.br/organizacao-de-frente-parlamentarpara-auditoria-da-divida-publica/.

${ }^{9}$ A dívida pública decompõe-se em dívida interna e externa: "A dívida interna de um país é usualmente traduzida na moeda do país. Para reembolsar a dívida, o Estado pode, por exemplo, imprimir papel-moeda, elevar os impostos ou baixar as taxas de juros [...]. A dívida externa dos PEDs [Países Em Desenvolvimento] decompõe-se em dívida externa pública e dívida externa privada. A primeira é contraída pelos poderes públicos - Estados, coletividades locais ou organismos públicos - ou por organismos privados cuja dívida é garantida pelo Estado. A dívida externa privada é contraída por organismos privados, por exemplo, pela filial de uma multinacional do Norte, e não é garantida pelo Estado" (MILLET; TOUSSAINT, 2006, p. 44). 
De acordo com o Museus em Números, 67,2\% dos museus no Brasil são públicos. Por isso, não é forçoso inferir, a partir desses percentuais, que existe uma fortíssima correlação entre os gastos do pagamento dos juros e amortizações da dívida pública e o investimento nos museus públicos brasileiros.

Podemos ver logo a seguir ${ }^{10}$, mais detalhadamente, como estão distribuídos os museus por natureza administrativa.

\section{Gráfico 1 - Porcentagem (\%) de museus por categorias de} natureza administrativa, Brasil, 2010.

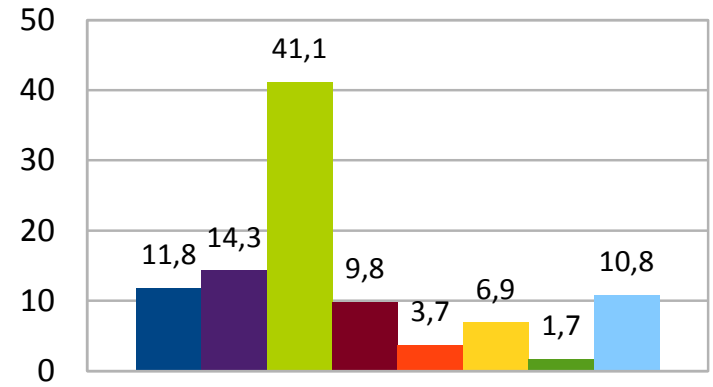

- Federal

Estadual

Municipal

Associação

Empresa

Fundação

Para Myrian Sepúlveda dos Santos, a construção de um campo museal devia, necessariamente, ser pensada a partir de políticas culturais desenvolvidas pelo Estado. No entanto, observava a seguinte tendência do Estado:

No Brasil, tem sido clara a tentativa do Estado de diminuir sua intervenção nas instituições culturais. Desde 1991, por exemplo, a Lei Rouanet ${ }^{11}$ ( $n$. 8313/91) permite que pessoas físicas e jurídicas possam investir na área da cultura e abater esta quantia do imposto devido (2004, p. 68).

\footnotetext{
${ }^{10}$ Gráfico adaptado do Museus em Números 1 (2011a).

${ }^{11}$ Conforme assinala Amazonas, "atualmente, as principais formas de financiamento do setor museológico são a utilização da Lei Federal de Incentivo à Cultura (Lei no 8.313/91), conhecida como Lei Rouanet, e os editais públicos e privados" (2010, p. 211).
} 
Nilson Moraes (2011), estudando as políticas públicas no Brasil, reconheceu "que as mudanças adotadas a partir de 2003 não significaram uma ruptura com o modelo social predominante anteriormente". Entretanto, reivindica que as políticas no período lulista, embora não sejam radicais àquelas instituídas no governo de Fernando Henrique Cardoso, foram radicais no sentido e no processo de seu desenvolvimento:

Elas - inicialmente - não são produtos prontos e transplantados. São decisões e modos de encaminhamento compartilhados e marcados pela presença e pelo compromisso do Estado com a sociedade civil e interesses envolvidos no setor. Neste sentido, as políticas do MinC nos Governos Lula foram originais, e não obedientes às agências internacionais e empresas nacionais como as adotadas no governo anterior (2011, p. 86).

De forma um tanto embaraçosa, Moraes argumenta que as políticas públicas no período lulista não apresentam rupturas, e nem se opõem ao governo FHC, caracterizado como um governo de corte neoliberal. Entretanto, para o sociólogo, o "novo [governo] não exclui[u] o antigo", mas firmou "um compromisso de respeito e de constituição democrática e participativa" (2011, p. 86).

Para compreender esse período, recorro às conclusões de Braga acerca da hegemonia lulista:

O reformismo petista deixou de ser plebeu para transformar-se em um reformismo (quase sem reformas) de gabinetes. No entanto, da mesma maneira que a reprodução do regime de acumulação despótico alimentou a inquietação operária, pressionando a regulação populista, também o atual regime de acumulação financeirizado pressiona a 
regulação lulista, complexificando a reprodução das condições sociais de produção do trabalho barato no país (2012, p. 230).

A desaceleração do crescimento econômico nacional e o acúmulo das contradições advindas da construção de uma hegemonia às avessas (para utilizar a famosa tese do sociólogo Francisco de Oliveira) pautada numa burocracia sindical de cunho rentista, aumentaram a angústia do precariado. É ilustrativo que, no período 2003-2013, 94\% dos empregos formais criados foram de até 1,5 salários mínimos (ANTUNES; BRAGA, 2013). Ou seja, o crescimento do emprego formal nos últimos anos significou a expansão do trabalho precarizado no país, fortemente concentrado no setor de serviços.

Para Braga, a dialética do lulismo consistiu no seguinte:

[...] combinar o consentimento passivo das massas que, seduzidas pelas políticas públicas redistributivas e pelos modestos ganhos salariais advindos do crescimento econômico, aderiram momentaneamente ao governo - com o consentimento ativo das direções sindicais - seduzidas por posições no aparato estatal, fora as incontáveis vantagens materiais proporcionadas pelo controle dos fundos de pensão $(2012$, p. 37).

As denominadas Jornadas de Junho no ano de 2013 marcaram o desafino no coro do puro consentimento com a entrada do precariado no cenário político. Mas já haviam antecedentes de contínua insatisfação da classe que vive do trabalho, no país. De 2010 a 2013 houve um aumento no número de greves no país. Em 2010 houve 446 greves, no ano seguinte houve 554 greves, em 2012 houve 873 greves, e em 2013 houve 2.050 greves por todo o país, marcando uma inflexão nas lutas no país. No que se refere ao funcionalismo público, houve um crescimento de $134 \%$ em relação ao ano de 2012, com 796 
greves no ano ${ }^{12}$ (DIEESE, 2015).

A orientação neoliberal foi continuada no governo lulista. De tal sorte, Santos reconhece que:

[...] a redução da política cultural às leis de incentivo fiscal deixa evidente a fragilidade da infra-estrutura que apoia e regula os museus. A retração do Estado em relação às políticas intervencionistas relativas à cultura representou não só a "não intervenção", como também o fortalecimento de regras de mercado sobre um campo fracamente estruturado (2004, p. 68).

Assim também analisam Salgado, Pedra e Caldas, ao afirmarem que "o governo Lula, embora tenha implementado uma nova política cultural no País, manteve praticamente o mesmo modelo de financiamento à cultura. Um modelo no qual prevalece o incentivo fiscal e a dedução de 100\%" (2010, p. 95).

Os recursos incentivados são separados em renúncia fiscal, ou seja, imposto que deixou de ser arrecadado, e dinheiro novo que é a parte adicional do empresário. Como exemplo, em um projeto de $\mathrm{R} \$ 400$ mil, $\mathrm{R} \$ 300$ mil correspondem à renúncia e $\mathrm{R} \$ 100 \mathrm{mil}$ à parte adicional do empresário [...] A renúncia cresce a uma média anual de $1,1 \%$, enquanto o adicional do empresário declinou, de uma participação de $66 \%$ dos recursos incentivados, para $23,7 \%$, em pouco mais de cinco anos (SALGADO; PEDRA; CALDAS, 2010, p. 96).

Os oito anos de governo Lula caracterizaram-se por um cenário econômico favorável para a adoção de uma política econômica que - sem jamais pôr em risco o lucro dos grandes

${ }^{12}$ Aqui cabe destacar a forte greve protagonizada pelos servidores públicos federais ligados ao Ministério da Cultura, no primeiro semestre de 2014, expondo a luta desses trabalhadores por melhores salários e condições de trabalho e revelando o estado de degradação de muitos museus brasileiros. 
capitalistas nacionais e internacionais - propiciou relativo crescimento no investimento em políticas públicas que impactaram direta ou indiretamente a Cultura.

No entanto, se havia alguma esperança na democratização do financiamento da Cultura no país, e no aumento do investimento direto estatal na Cultura, ela findou logo no início do governo de Dilma Roussef (PT). Em recente artigo, sintomaticamente intitulado Políticas culturais no primeiro governo Dilma: patamar rebaixado, Antonio Rubim faz o seguinte balanço:

A política de financiamento foi esquecida e desconsiderada de modo preocupante. Hoje as leis de incentivo representam cerca de $80 \%$ do financiamento do Estado Nacional para a cultura no Brasil e o FNC perfaz apenas aproximadamente $20 \%$ do financiamento. Esta composição da política de financiamento, que sintomaticamente permaneceu sem mudanças nos últimos 12 anos, coloca em perigo as políticas para a diversidade cultural, implantadas desde 2003, e inviabiliza o desenvolvimento do SNC, que não pode prescindir de recursos públicos federais, dentre outros, para a sua construção $(2015$, p. 21$)$.

Não é possível tratar nesse espaço das diversas políticas públicas para a cultura ${ }^{13}$, mas é salutar observar a política por outro ângulo: embora as vagas neoliberais lancem sucessivas ofensivas contra o Estado, é o Estado quem realiza, politicamente, a liberalização da economia ${ }^{14}$. Em estudo sobre

\footnotetext{
${ }^{13} \operatorname{Ver}($ RUBIM; BARBALHO; CALABRE, 2015) e (RUBIM, 2010).

${ }^{14}$ Para ilustrar, a adoção das políticas neoliberais de desregulamentação da economia e de sistemática privatização de serviços e empresas públicas no Brasil, durante o período 1990-2013, foram levadas adiante, em grande medida, mediante à força do Estado na alteração (e acréscimo) de dispositivos constitucionais, do uso dos aparelhos ideológicos na modulação da opinião pública e do uso da repressão contra os trabalhadores organizados e a juventude.
} 
os trabalhadores de apoio técnico no Theatro Municipal de São Paulo, Maria Aparecida Alves chamou atenção para o papel cumprido pelas mudanças nas políticas públicas para a Cultura na precarização do trabalho no Theatro Municipal. Para Alves:

Em consequência das mudanças na forma de financiamento público da cultura, que prioriza a captação de recursos na esfera privada, a produção dos espetáculos passa a adotar práticas que modificam a composição básica ou tradicional das profissões que fazem parte do processo de produção de espetáculos, reduzindo os ofícios de caráter mais especificamente manuais e técnicos em benefício daquelas profissões ligadas à captação de recursos e marketing. Nesse sentido, a partir da segunda metade da década de 1990, no Theatro Municipal, houve estímulo à ampliação das formas de terceirização dos trabalhos relativos à criação e confecção dos figurinos, cenários e adereços: a contratação por projetos foi priorizada, já que, dessa forma, a instituição não necessitaria ampliar as equipes de apoio aos espetáculos. Esse mecanismo permite ao teatro transferir a responsabilidade da contratação e manutenção de profissionais dessa área para os ateliês particulares (2014, p. 269).

Portanto, é impossível compreender a privatização da Cultura, e a precarização do trabalho nos museus, sem levar em conta o papel desempenhado pelo Estado. Cumpre agora, analisar algumas das principais características da precarização nos museus brasileiros, considerando especialmente os trabalhadores museólogos.

\section{Precarização do trabalho: um desafio para os novos museólogos}

Os dados sobre os trabalhadores museólogos brasileiros ainda são insuficientes, o que torna difícil, por exemplo, 
mensurar com mais precisão o seu quantitativo em números absolutos, bem como, observar outras variáveis como faixa etária, gênero, cor/raça etc. Contudo, alguns dados sobre o alunado podem nos auxiliar a mensurar, aproximadamente, uma ou outra característica dos museólogos.

De acordo com os dados da Sinopse da Educação Superior do Instituto Nacional de Estudos e Pesquisas Educacionais Anísio Teixeira (INEP) de 2011, havia no Brasil 1688 alunas/os matriculadas/os nos cursos presenciais de graduação em Museologia, sendo que 1210 são do gênero feminino, perfazendo $71 \%$ das/os estudantes matriculadas/os nos cursos de Museologia no país. Dos 543 concluintes entre os anos de 2000-2011, 419 eram do gênero feminino, perfazendo 77,1\% dos bacharéis formados em Museologia nesse período.

Já no que se refere à faixa faixa etária dos trabalhadores das instituições museais brasileiras analisadas no estudo Museus e a dimensão econômica, do IBRAM, 56,4\% dos trabalhadores possuem entre 18 a 39 anos.

De acordo com os dados coletados ${ }^{15}$ com 99 museólogos localizados no Rio de Janeiro - a sua maioria é composta por jovens (entre 21 - 30 anos, representando 62\%), de sexo feminino (74\%) e branca (62\%). Esses dados amostrais nos aproximam das estimativas nacionais apresentadas anteriormente e ajudam a ilustrar as principais características do

\footnotetext{
${ }^{15}$ Foi construído um questionário com perguntas de caráter aberto e fechado utilizando a ferramenta de construção de questionários chamada Google Drive. Submetemos o questionário aos museólogos através da internet, hospedando o link na página Concursos Museologia. Um blog gerido por três museólogos que tornou-se "um canal de informação sobre concurso público, oportunidades de trabalho e estudo na área de Museologia no Brasil". Escolhemos hospedar o link para o questionário de nossa pesquisa na página Concursos Museologia pois esse blog atrai a atenção de centenas de museólogos espalhados pelo Brasil, registrando periodicamente milhares de visitações, especialmente, por reunir e publicar as principais ofertas de trabalho para museólogos e graduandos.
} 
trabalhador museólogo: é jovem e majoritariamente feminino.

Como vimos, essas são duas das principais variáveis que caracterizam os trabalhadores precarizados. Embora isso não seja suficiente para localizar os museólogos no conjunto de trabalhadores precarizados, ou ainda, do precariado, veremos que é fundamental ter isso mente ao analisar os (des)caminhos dos trabalhadores museólogos.

Vejamos em seguida como se apresenta a distribuição dos profissionais nas instituições museológicas a partir dos tipos de vínculos.

\section{Tabela 2 - Trabalhadores de instituições museológicas por tipo de vínculo ${ }^{16}$}

\begin{tabular}{|c|c|c|c|c|c|c|c|c|}
\hline \multicolumn{9}{|c|}{ VÍNCULO } \\
\hline 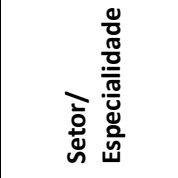 & 莣 & $\begin{array}{l}\text { 음 } \\
\frac{0}{0} \\
\text { Un }\end{array}$ & 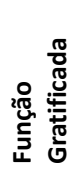 & 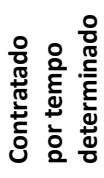 & 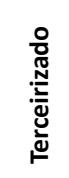 & $\begin{array}{l}\stackrel{0}{\frac{0}{2}} \\
\stackrel{\frac{\pi}{5}}{5} \\
\frac{3}{0} \\
5\end{array}$ & 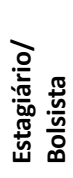 & $\begin{array}{l}\circ \\
\stackrel{2}{*} \\
0\end{array}$ \\
\hline Diretoria & 627 & 73 & 335 & 110 & 37 & 409 & 38 & 77 \\
\hline Museólogo & 232 & 23 & 25 & 33 & 23 & 49 & 86 & 6 \\
\hline Bibliotecário & 191 & 37 & 20 & 29 & 23 & 33 & 78 & 13 \\
\hline Arquivista & 153 & 17 & 7 & 16 & 12 & 35 & 59 & 2 \\
\hline Conservador & 177 & 39 & 21 & 46 & 77 & 32 & 18 & 30 \\
\hline Pedagogo & 166 & 56 & 14 & 36 & 34 & 53 & 44 & 3 \\
\hline Historiador & 307 & 57 & 39 & 50 & 36 & 88 & 273 & 9 \\
\hline Arquiteto & 48 & 9 & 6 & 18 & 15 & 26 & 22 & 7 \\
\hline Antropólogo & 55 & 3 & 2 & 10 & 4 & 7 & 11 & 3 \\
\hline Administrativo & 2040 & 153 & 305 & 261 & 321 & 99 & 336 & 53 \\
\hline Manutenção & 1215 & 141 & 434 & 265 & 1086 & 160 & 6 & 45 \\
\hline
\end{tabular}

${ }^{16}$ Tabela adaptada do Museus em Números 1 (2011a, p. 139). 


\begin{tabular}{|l|c|c|c|c|c|c|c|c|}
\hline Limpeza & 1294 & 200 & 23 & 111 & 1185 & 45 & 6 & 35 \\
\hline Segurança & 1190 & 190 & 40 & 68 & 1599 & 17 & 2 & 32 \\
\hline Outros & 1581 & 134 & 75 & 281 & 389 & 476 & 1492 & 191 \\
\hline
\end{tabular}

É importante destacar que nessa pesquisa foram incluídos todos os profissionais formados ou em vias de formação que exercem atividades regulares na instituição independente do seu vínculo, incluindo assim, categorias relacionadas a estágio/bolsas e voluntariado.

Alguns dados chamam bastante a atenção nessa tabela. Em primeiro lugar, o número expressivo de funcionários terceirizados nos setores de manutenção, limpeza e segurança. No caso da segurança, mais da metade do contingente de trabalhadores é terceirizado. Em segundo lugar, chama a atenção a variação dos vínculos nos cargos de diretoria, função estratégica em museus. Observa-se que o número de diretores efetivos é de 627, contratados temporariamente são 110 , terceirizados 37, voluntários são 409, estagiário/bolsista 38 e outras modalidades representam 77 . Vale destacar também que o número de historiadores estagiários/bolsistas (273) se aproxima do quantitativo de efetivos (307).

Em terceiro lugar, a disposição dos museólogos e conservadores observa uma grande variação de acordo com os tipos de vínculos. O número de museólogos não-efetivos fica um pouco abaixo dos efetivos. Os museólogos efetivos somam 232, contratados por tempo determinado 33, terceirizados são 23, voluntários 49, estagiários/bolsistas 86 e outras modalidades somam 6. No tocante aos conservadores, mais da metade dos funcionários não são efetivos, com expressivo número de trabalhadores terceirizados, voluntários e sob contratos temporários. É importante destacar que existe uma grande filiação profissional entre a Conservação e a Museologia, não só em termos de confluência de saberes, mas de competências, com razoável número de museólogos de formação enquadrados como 
conservadores.

O maior seguimento de funcionários por atividade - com 4.619 - é definido apenas como "outros". Um segmento que possui, nada menos, do que 1.492 funcionários com vínculos de estagiários/bolsista, representando $32 \%$ do número total de funcionários; contando ainda com 476 voluntários e 389 terceirizados.

Por último, observa-se que $43 \%$ dos trabalhadores que atuam nos museus brasileiros possuem os seguintes vínculos empregatícios ${ }^{17}$ : contratado por tempo determinado, terceirizado, voluntário e estagiário. Considerando apenas os trabalhadores museólogos, chegamos a um percentual de $40 \%$ sob esses quatro tipos de vínculos. Isso nos indica que, em linhas gerais, muitos museólogos trabalham em condições de informalidade nos museus brasileiros.

Uma vez que concebemos a informalidade como ruptura com os laços formais de contratação $e$ regulação da força de trabalho, podemos acrescentar que, se a informalidade não é sinônimo direto de condição de precariedade, sua vigência expressa, com grande frequência e intensidade, formas de trabalho desprovidas de direitos, as quais, portanto, apresentam clara similitude com a precarização (ANTUNES, 2013, p. 17).

O acentuado percentual feminino dos trabalhadores museólogos é uma variável importante na consideração da informalidade ou subcontratação dos museólogos brasileiros. Conforme Claudia Mazzei Nogueira ressalta, a precarização do

${ }^{17}$ Diferencio em dois grupos o quadro apresentado pelo Museus em Números 1: o primeiro grupo abrange os trabalhadores efetivos, cedidos, e que possuem funções gratificadas. O segundo grupo é composto pelos trabalhadores contratados por tempo determinado, terceirizados, voluntários e estagiários/bolsistas. 
trabalho atinge majoritariamente as mulheres (2009). Ademais, o economista Guy Standing, há uma tendência global de feminização do trabalho, onde há um aumento no número de mulheres empregadas e um aumento no número de empregos flexíveis. Em suas palavras:

Se o trabalho flexível significa mais empregos de curta duração, isso quer dizer que há poucas vantagens nos empregos tidos como masculinos e vistos - correta ou incorretamente - como empregos que oferecem compromisso de longo prazo. O temor de que as mulheres possam envolver empregadores em altos custos não salariais, porque podem engravidar ou se ausentar para cuidar dos filhos, é menos relevante quando os empregos têm duração definida de poucos meses, se o acordo não é vinculativo ou dependente de demanda flutuante, ou se não houver nenhum custo para o trabalho intermitente (2014, p. 98-99).

Além disso, $18 \%$ dos museólogos dos museus, conforme a tabela, são estagiários ou bolsistas. Vale a pena incidir, ainda que brevemente, sobre esse ponto.

Para Standing (2014), os estágios moveram-se furtivamente para dentro da política do mercado:

[...] está se espalhando uma nova forma de trabalho precariado especialmente designada para a juventude. $\mathrm{O}$ emprego probatório à moda antiga, pelo menos em princípio, levou a empregos estáveis como aconteceu com a aprendizagem de ofícios. Os estágios não. Eles são apresentados como uma forma de ganhar experiência útil destinada a fornecer, direta ou indiretamente, uma entrada potencial para um emprego regular. Na prática, eles são usados por muitos empregadores como um meio de obter trabalho dispensável barato (2014, p. 120). 
Nas palavras de Standing (2014), os estagiários acabam se tornando substitutos precariados para o emprego regular. Realizam trabalhos com baixa remuneração e sem perspectivas de progresso, impelindo a uma política de rebaixamento dos salários e reduzindo oportunidades de geração de postos de trabalho formal. O que, de forma alguma, deve ser imputado aos jovens, mas antes, a uma política de incorporação dessa atividade numa lógica de precarização estrutural do trabalho.

A incorporação dos estágios para dentro da política do mercado de trabalho revela, também, o fortalecimento dos liames entre as instituições de ensino e o mercado, na conformação de uma relação onde o mercado define as prioridades daquelas.

\section{Considerações finais}

Os números apresentados dão uma boa ideia da composição laboral dentro dos museus, instituições marcadamente interdisciplinares. Contudo, ainda carecemos de maiores investigações acerca dos trabalhadores museólogos.

Considero importante que desenvolvamos pesquisas capazes de analisar, mais de perto, as condições de trabalho dos museólogos. Ouso apenas fazer algumas indicações: 1) a característica marcadamente feminina do conjunto dos trabalhadores museólogos impõe estudos que conectem a feminização do trabalho mundial e do trabalho precarizado à trajetória das trabalhadoras museólogas no mercado de trabalho; 2) o avanço do trabalho precarizado e das terceirizações nos museus brasileiros deve ser analisado, dentre outras formas, considerando-se as políticas públicas para os museus no país; 3) a combinação entre a diminuição dos investimentos públicos estatais e a "redução da política cultural às leis de incentivo fiscal", assinalada por Santos (2004, p. 86), pode produzir uma crescente assimetria no cenário museal brasileiro: com muitos museus em situações econômicas críticas e com crescente 
precarização dos seus profissionais; ao passo em que, poucos museus - capazes de se alinhar às tendências de mercado - se tornarão instituições economicamente mais rentáveis.

\section{Referências}

AMAZONAS, Archimedes Ribas. Políticas de Museus. In: RUBIM, Antonio A. Canelas (Org). Políticas culturais no governo Lula. Salvador: EDUFBA, 2010.

ANTUNES, Ricardo. Os sentidos do trabalho: ensaio sobre a afirmação e a negação do trabalho. São Paulo: Boitempo, 2009. ANTUNES, Ricardo. Dimensões da precarização estrutural do trabalho. In: DRUCK, Graça.; FRANCO, Tânia (Orgs.) A perda da razão social do trabalho: terceirização e precarização. São Paulo: Boitempo, 2007.

ANTUNES, Ricardo. A nova morfologia do trabalho e suas principais tendências. In: ANTUNES, Ricardo (Org.). Riqueza e Miséria do trabalho no Brasil II. São Paulo: Boitempo, 2013. ANTUNES, Ricardo; BRAGA, Ruy. La explosión social en Brasil: Primeras anotaciones (para un análisis posterior). Nuestra America. № 35, jul 2013. Colômbia: 2013.

$B B C$. Informais podem ser dois terços da força de trabalho em 2020, diz OCDE. Disponível em:

www.bbc.co.uk/portuguese/noticias/2009/04/090408_ empregoinformalocdefn.shtml. Acesso em: 25 jun 2012. BRAGA, Ruy. A política do precariado: do populismo à hegemonia lulista. São Paulo: Boitempo, 2012.

DIEESE. Balanço das greves em 2013. Estudos e Pesquisas. São Paulo: DIEESE, 2015, n 79.

IBGE. Censo Agropecuário 2006. Rio de Janeiro: IBGE, 2009. IBGE. Sinopse do Censo Demográfico 2010. Rio de Janeiro: Ministério do Planejamento, Orçamento e Gestão, 2011. IBGE. Síntese dos Indicadores Sociais. Rio de Janeiro: Ministério do Planejamento, Orçamento e Gestão, 2010. 
IBRAM. Museus e a dimensão econômica: da cadeia produtiva à gestão sustentável. Brasília: IBRAM, 2014.

IBRAM. Museus em números volume 1. Brasília: IBRAM, 2011. ILO. Global Employment and Trends 2012. Disponível em:

http://www.ilo.org/global/publications/lang-en/index.htm.

Acesso em: 13 jul 2012. Geneva: ILO, 2012.

MARX, Karl. Manuscritos econômico-filosóficos. São Paulo:

Boitempo, 2009.

MARX, Karl. O Capital: Crítica da Economia Política (Livro 1, Vol.

1). Rio de Janeiro:

Civilização Brasileira, 2008.

MARX, Karl. O Capital: Crítica da Economia Política (Livro 1, Vol.

2). Rio de Janeiro:

Civilização Brasileira, 2008.

MILLET, Demian; TOUSSAINT, Eric. 50 perguntas 50 respostas:

sobre a dívida, o FMI e o Banco Mundial. São Paulo: Boitempo, 2006.

MORAES, Nilson. Museu, poder e políticas culturais no Brasil.

Musas - Revista Brasileira de Museus e Museologia, Brasília, n. 5, 2011.

NOGUEIRA, Claudia M. As trabalhadoras do telemarketing: uma nova divisão sexual do trabalho? In: ANTUNES, Ricardo; BRAGA, Ruy (Org). Infoproletários: degradação real do trabalho virtual. São Paulo: Boitempo, 2009.

OECD. Statistics from A to Z. Disponível em:

http://www.oecd.org/document/0,3746,en 26492011854646 27591111 1,00.html. Acesso em: 06 jul 2012.

PNAD. Pesquisa Nacional por Amostras de Domicílios 2009. Rio de Janeiro: IBGE, 2011.

PORTO-GONÇALVES, Carlos W. A globalização da natureza e a natureza da globalização. Rio de Janeiro: Civilização Brasileira, 2006.

RUBIM, Antonio A. Canelas (Org). Políticas culturais no governo Lula. Salvador: EDUFBA, 2010. 
RUBIM, Antonio A. Canelas; CALABRE, Lia (Org). Políticas culturais no governo Dilma. Salvador: EDUFBA, 2015. RUBIM, Antonio A. Canelas. Políticas culturais no primeiro governo Dilma: patamar rebaixado. In: RUBIM, Antonio A. Canelas; CALABRE, Lia (Org). Políticas culturais no governo Dilma. Salvador: EDUFBA, 2015.

SALGADO, Gabriel; PEDRA, Layno; CALDAS, Rebeca. As políticas de financiamento à cultura: a urgência de uma reforma. In: RUBIM, Antonio A. Canelas (Org). Políticas culturais no governo Lula. Salvador: EDUFBA, 2010.

SANTOS, Myrian. Museus brasileiros e política cultural. Revista Brasileira de Ciências Sociais, Brasil, v. 19, n. 55, 2004. STANDING, Guy. O Precariado: a nova classe perigosa. Belo Horizonte: Autêntica, 2014. 